\title{
Method Development and Characterization of Liposomal Formulation of Isotretinoin
}

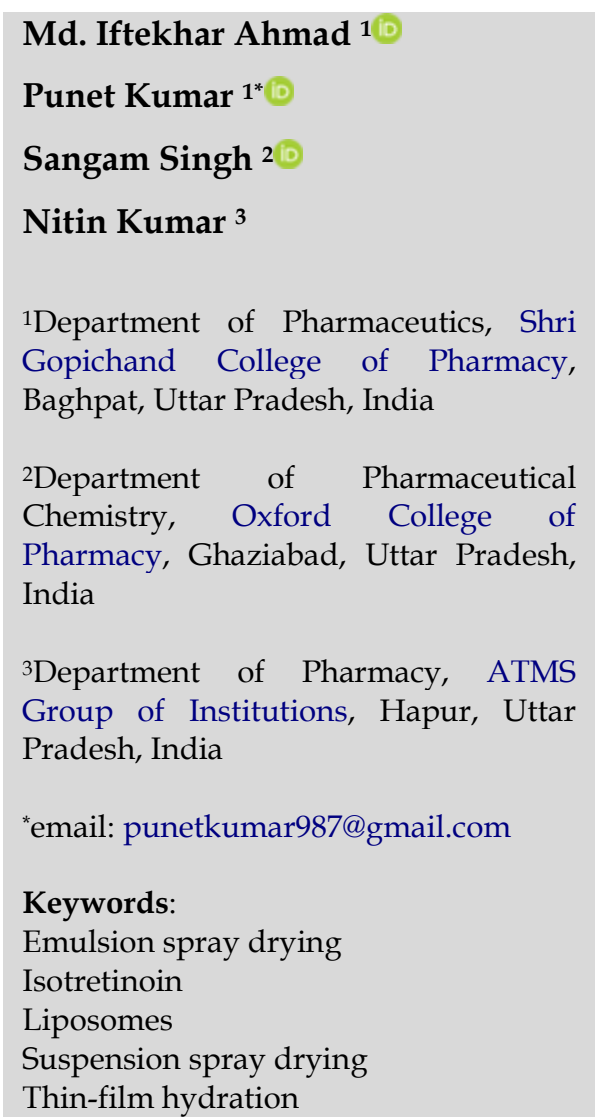

\begin{abstract}
This study aims to develop a liposomal drug delivery system of isotretinoin, an acne drug-using spray drying, as a cost-effective and time-effective technique. The liposomal formulation was prepared by using spray drying; three different strategies were adopted: suspension spray drying (SSD), thin-film hydration and spray drying (TFHSD), and emulsion spray drying (ESD). Isotretinoin was $99 \%$ bound with lipid, so lipids hydrogenated soy phosphatidylcholine (HSPC), distearoyl phosphatidylglycerol (DSPG), and cholesterol were selected for the formulation development. The HSPC, DSPG, cholesterol, and isotretinoin were taken in the ratio $4: 1: 0.16: 3.1$ mmol. In vitro drug release studies, microscopy, drug content, and related substance characterizations were done to formulate each strategy of spray drying prepared dry liposomes of isotretinoin. Results were compared with the USP monograph of isotretinoin. It was revealed that isotretinoin's liposomal formulation using ESD was having drug release according to the USP limits. Drug content was also according to the USP requirement; no free drug crystals were found in microscopy, multivesicular vesicles were found in shape, a particle size of up $60 \mu$ was found. The ESD technique was a successful, time-effective, and cost-effective technique for preparing a liposomal drug delivery system for isotretinoin.
\end{abstract}

Received: December $11^{\text {th }}, 2020$

Accepted: April 1st, 2021

Published: May 30th 2021

(C) 2021 Md. Iftekhar Ahmad, Punet Kumar, Sangam Singh, Nitin Kumar. Published by Institute for Research and Community Services Universitas Muhammadiyah Palangkaraya. This is an Open Access article under the CC-BYSA License (http://creativecommons.org/licenses/by-sa/4.0/). DOI: https://doi.org/10.33084/bjop.v4i2.1915

\section{INTRODUCTION}

Acne vulgaris is a widespread skin disorder among adolescents, and it affects $90 \%$ of the individual at some point in their life ${ }^{1}$. Its chronic condition leads to an increase in sebum production, resulting in keratinization changes, inflammation under hair follicles by Propionibacterium acnes. Acne persists for a very long time with depressing consequences in adults ${ }^{23}$. Acne is commonly treated using benzoyl peroxide, topical antibiotics (erythromycin and clindamycin), and topical retinoid (tretinoin, isotretinoin, retinaldehyde, and retinoyl $\beta$-glucuronide) $)^{4}$.
Isotretinoin is a crystalline yellowish-orange powder with a faint odor 5 . The isotretinoin powder is soluble in chloroform and methylene chloride and sparingly soluble in water6. Isotretinoin incites apoptosis (cell death) in different parts of the body cells. Apoptosis may induce hippocampus cells, hypothalamic cells, meibomian gland, and vital in acne therapy in sebaceous gland cells $3,7,8$. Isotretinoin has modest interaction for retinoid $X$ receptors $(R X R)$ and retinoic acid receptors (RAR) but might transform intracellularly to metabolites that mimic an agonist RXR nuclear receptors and RAR 9 . Isotretinoin is the exclusive acne drug available which influences all vital pathogenic action in acne; it 
differentiates from antibiotics treatments and considers its therapeutic efficacy in severe, nodulocystic cases. The repercussions of isotretinoin on sebum output can be short-term, or remission of the disease can be absolute and for an extended period ${ }^{10}$.

Liposomes are small artificial vesicles of the spherical shape created from cholesterol and natural, nontoxic phospholipids ${ }^{11,12}$. Due to their size and hydrophobic and hydrophilic character (besides biocompatibility), liposomes are promising systems for drug delivery. Liposomes are extensively used as carriers for numerous molecules in the cosmetic and pharmaceutical industries ${ }^{13,14}$.

A liposomal drug delivery system was developed for isotretinoin using the spray drying technique ${ }^{15}$. Spraydrying using a two-fluid nozzle was tested to dry liposome preparations, i.e., liposomes composed of hydrogenated soy phosphatidylcholine (HSPC), distearoyl phosphatidylglycerol (DSPG), cholesterol, and isotretinoin. Isotretinoin other products are available in the market, such as isotretinoin suspension capsules which are expensive ${ }^{16}$. Isotretinoin shows stability problems to overcome these problems and to prepare a cost-effective product to dry liposome of isotretinoin was prepared using spray drying technique ${ }^{17}$. Based on this background, this study aims to develop liposomal preparation of isotretinoin for acne by using the spray drying technique.

\section{MATERIALS AND METHODS}

\section{Materials}

Isotretinoin was obtained from Sun Pharmaceuticals, Gurgaon, Haryana, India. All solvents (distilled water, methanol, and chloroform) were purchased from $\mathrm{CDH}$ (Central Drug House Pvt. Ltd, New Delhi, India). Other ingredients include borate buffer, HSPC, DSPG, cholesterol, butylated hydroxyanisole (BHA), butylated hydroxytoluene (BHT), mannitol, propyl gallate, and phosphate buffer. The instruments used include the UV spectrophotometer (Shimadzu), mini spray dryer B-290 (Buchi), Eclipse E600POL microscope (Nikon), differential scanning calorimeter (DSC, Shimadzu), rotary evaporator, high-pressure homogenizer $(\mathrm{HPH})$, and dissolution test apparatus type II (paddle).

\section{Methods}

Physical characterization of isotretinoin

Solubility - The saturation solubility studies of class II model drug-like isotretinoin were conducted as per Biopharmaceutics Classification System (BCS) guidelines ${ }^{18}$. An excess amount of isotretinoin was placed in $\mathrm{pH}$ borate buffer at room temperature and stirred until saturation point. After 24 hours, the sample was filtered, suitably diluted, and absorbance was taken at $346 \mathrm{~nm}$ against $\mathrm{pH} 8$ borate buffer as blank on UV spectrophotometer. The excipient and drug solubility were observed in the solvent, i.e., water, methanol, and chloroform, to optimize the ratio of solvent combination, i.e., chloroform : methanol $(1: 1)$ and chloroform : methanol $(2: 1)$.

Quantitative estimation of isotretinoin - The UV spectrophotometric method was used to estimate the drug because the method was simple, economical, and gives reproducible results within acceptable limits. The double beam UV spectrophotometer was used for analysis ${ }^{19}$. Isotretinoin was dissolved in borate buffer $\mathrm{pH}$ 8.0 containing $0.5 \%$ cetrimide. The solution was scanned for maximum absorbance in a UV double beam spectrophotometer in the range from 200 to $400 \mathrm{~nm}$, using the respective solution as a blank.

Selection of lipids - Optimization batches were prepared to optimize the number of lipids. Initially, the quantities were taken in 2:1 mmol of HSPC and cholesterol, respectively. The Amount of DSPG was kept constant at 
$0.16 \mathrm{mmol}$. Tests were carried out on three batches with variations in the number of HSPCs, as shown in Table I.

\begin{tabular}{cccc} 
Table I. & \multicolumn{2}{c}{$\begin{array}{c}\text { Optimization of lipids use for } \\
\text { development of different batches }\end{array}$} & formulation \\
\hline \multirow{3}{*}{ Batch } & \multicolumn{4}{|c}{ Ingredients } \\
\cline { 2 - 4 } & $\begin{array}{c}\text { HSPC } \\
\text { (mmol) }\end{array}$ & $\begin{array}{c}\text { Cholesterol } \\
\text { (mmol) }\end{array}$ & $\begin{array}{c}\text { DSPG } \\
\text { (mmol) }\end{array}$ \\
\hline 1 & 2 & 1 & 0.16 \\
2 & 3 & 1 & 0.16 \\
3 & 4 & 1 & 0.16 \\
\hline
\end{tabular}

Excipients were dissolved in the solvent and then spraydried by mini spray dryer B-290 with an inlet temperature of $70^{\circ} \mathrm{C}$, the outlet temperature of $42^{\circ} \mathrm{C}$, aspirator rate was kept at $70 \%$, nitrogen pressure was at $2 \mathrm{~kg} / \mathrm{cm}^{2}$, and pump rate kept at 5\%. The spray-dried powder was collected and dispersed in an appropriate amount of water and then observed under a microscope using a $50 \times$ lens.

Drug loading - Pre-optimization studies of isotretinoin liposomal formulation were tried to formulatealong with the lipids, HSPC, DSPG, and cholesterol to optimize the drug loading for the isotretinoin liposome formulation. A review of the literature revealed that these were the lipids that can be used in formulation development. Thus, for selection of the range, various pre-optimization trials were done with the exact quantities of lipids but with the increasing quantity of isotretinoin ${ }^{20}$, as shown in Table II.

Table II. Pre-optimization trials of various batches

\begin{tabular}{|c|c|c|c|c|}
\hline \multirow[b]{2}{*}{ Batch } & \multicolumn{4}{|c|}{ Ingredients } \\
\hline & $\begin{array}{c}\text { HSPC } \\
(\mathrm{MW} \\
783.8 \\
\mathrm{~g} / \mathrm{mol})\end{array}$ & $\begin{array}{c}\text { Cholesterol } \\
\text { (MW 368.7 } \\
\text { g/mol) }\end{array}$ & $\begin{array}{c}\text { DSPG } \\
\text { (MW } \\
801 \\
\text { g/mol) }\end{array}$ & $\begin{array}{c}\text { Isotretinoin } \\
\text { (MW } 300.4 \\
\mathrm{~g} / \mathrm{mol})\end{array}$ \\
\hline 1 & 4 & 1 & 0.16 & 0.25 \\
\hline 2 & 4 & 1 & 0.16 & 0.5 \\
\hline 3 & 4 & 1 & 0.16 & 1 \\
\hline 4 & 4 & 1 & 0.16 & 1.4 \\
\hline 5 & 4 & 1 & 0.16 & 2.2 \\
\hline 6 & 4 & 1 & 0.16 & 3.1 \\
\hline
\end{tabular}

All ingredients were dissolved in chloroform : methanol (2:1) solvent and spray-dried at the same parameters used earlier in this study. Batches were manufactured with isotretinoin quantities of $0.25 \mathrm{mmol}$ to $3.1 \mathrm{mmol}$ to check the solubility of the drug in a given excipient. Resulted in dried drug lipid dry powder was dispersed in phosphate buffer $\mathrm{pH} 6.8$ and observed for multivesicular vesicles and free drug crystals using a microscope with a $50 X$ lens.

Differential scanning calorimetry - Differential scanning calorimetry experiments were performed with DSC. Sample of isotretinoin and spray dried liposomal formulation containing isotretinoin and lipids (HSPC, DSPG, and cholesterol) were submitted to DSC analysis. The analysis was performed on $5 \mathrm{mg}$ samples sealed in standard aluminum pans. Thermograms were obtained at a scanning rate of $10^{\circ} \mathrm{C} /$ minutes. Each sample was scanned between $0^{\circ} \mathrm{C}$ to $200^{\circ} \mathrm{C}$. The temperature of maximal heat capacity was defined as the phase transition temperature ${ }^{21}$.

\section{Preparation of liposomal formulation of isotretinoin}

Isotretinoin liposomes were prepared by using a spray drying technique. The spray drying technique was employed through three different strategies, i.e., suspension spray drying (SSD), thin-film hydration and spray drying (TFHSD), and emulsion spray drying (ESD).

\section{Suspension spray drying}

The solution of suspension spray drying was prepared by dissolving HSPC, cholesterol, DSPG, and isotretinoin in the ratio of $4: 1: 0.16: 3.1 \mathrm{~mol}$, respectively. These ingredients were dissolved in chloroform : methanol (2 : 1) solvent. The DSPG was dissolved in the solvent in the presence of heat $60^{\circ} \mathrm{C}$ to prevent aggregates formation. Ingredients other than DSPG are mixed with the swirling of the solution ${ }^{22}$. The suspension was spray-dried with a mini spray dryer B-290 combined with inert loop B-295 at the following parameter: inlet temperature $60-80^{\circ} \mathrm{C}$; outlet temperature $38-45^{\circ} \mathrm{C}$; aspirator rate at $50-70 \%$; pump rate at $5-10 \%$; and nitrogen pressure $2 \mathrm{~kg} / \mathrm{cm}^{2}$. The 
dried powder so retained from the spray drier was characterized further. The batch was named SSD 1.

Thin-film hydration and spray drying

The TFHSD technique's objective was to overcome the hygroscopicity problem that was coming in the previous $\mathrm{SSD}^{23}$. The TFHSD was conducted in several steps.

Preparation of solution - The solution for dispersion spray drying was prepared with the same composition and according to the optimized amount. This was done in the solution spray drying method. Antioxidants BHA and BHT was added within allowed daily intake limits.

Thin-film formation using rotary evaporator - Thin-film of the solution containing formulation was the suitable organic solution formed using the rotary evaporator at the following parameters: bath temperature $450^{\circ} \mathrm{C}$; RPM 30; vacuum 250-500 mm of $\mathrm{Hg}$ for 1 hour $^{24}$.

Hydration of thin-film with Buffer containing 5\% mannitol The hydration of the thin-film was prepared using phosphate buffers pH 6.8 and 5\% mannitol in it. The hydration was carried out for 1-2 hours. The appropriate amount of the buffer was put in the rotary evaporator vessel over the thin-film, so the formed process started again with temperature $50-55^{\circ} \mathrm{C}$, and vacuum was applied. If a problem occurs in hydration, sonication was performed to recollect the total amount of material ${ }^{24}$. The above suspension was passed through the $\mathrm{HPH}$ to reduce the size of the particles in the suspension.

Spray drying - The prepared suspension so obtained from HPH was then spray-dried using mini spray dryer B-290 with the following parameters: aspirator rate $70 \%$; inlet temperature $80^{\circ} \mathrm{C}$; outlet temperature $52^{\circ} \mathrm{C}$; and pump rate $5 \%$. The spray drying was performed using air as well as nitrogen. The dried powder was collected and was analyzed. This technique was employed to overcome the hygroscopicity ${ }^{25}$. Only related substance characterization was done of TFHSD. The batch was named TFHSD 1.

Emulsion spray drying

Emulsion spray drying was the technique in which emulsion was prepared by emulsifying organic solvent containing drug and lipids with water containing mannitol using high-speed homogenization ${ }^{25}$. The ESD was performed in several steps.

Preparation of the organic and aqueous phases - The organic phase and aqueous phase ratios were kept at 70\% and $30 \%$, respectively. The organic solution was prepared with the optimized quantities of the Excipient and the drug. The composition used was HSPC : cholesterol : DSPG : isotretinoin ( $4: 1: 0.16: 3.1 \mathrm{~mol}$, respectively), BHA, BHT, and propyl gallate (within allowed daily intake limits). These all were mixed in the solvent of chloroform and methanol (2:1), making 5\% w/w solution, and then processed further. Mannitol (2.5/5 times of drug quantity) was dissolved in a suitable amount of distilled water.

High-speed homogenization - The aqueous solution was added drop-wise to an organic solution under highspeed homogenization for speed up to 18000 RPM, resulting in an emulsion ${ }^{26}$. The homogenization was done for 5 minutes with breaks for 10 seconds after 2, 3, and 4 minutes in between to avoid overheating due to heat generation.

Spray drying - The prepared emulsion was then spray dried using the following parameters: inlet temperature $70^{\circ} \mathrm{C}$; outlet temperature $42^{\circ} \mathrm{C}$; aspirator rate $70 \%$; pump rate $5 \%$; nitrogen pressure $2 \mathrm{~kg} / \mathrm{cm}^{2}$; and humidity of room $55-60 \%$. The spray-dried powder was collected and filled in the hard gelatin capsules, and analyzed further. The batch was named ESD1. 
Physical characterization of isotretinoin liposomal formulation

Drug content - As much as $10 \mathrm{mg}$ of spray-dried powder was dissolved in $100 \mathrm{~mL}$ of solvent, i.e., chloroform : methanol (2:1) in a $100 \mathrm{~mL}$ volumetric flask. As much as $2 \mathrm{~mL}$ was taken from this solution and diluted up to 10 $\mathrm{mL}$ with the solvent in a $10 \mathrm{~mL}$ volumetric flask. The absorbance of the resulting solution was measured at the maximum at $346 \mathrm{~nm}$ using a UV spectrophotometer ${ }^{27}$. The linearity equation obtained from the calibration curve was used to estimate isotretinoin in the liposomal formulations. Results were compared with the USP monograph limits.

In vitro release studies - The release rate of $40 \mathrm{mg}$ capsule isotretinoin liposomal formulation was determined using type II dissolution test apparatus. The dissolution test was carried out using $900 \mathrm{~mL}$ of borate buffers $\mathrm{pH} 8$ with pancreatin at $37 \pm 0.5^{\circ} \mathrm{C}$ and $100 \mathrm{RPM}$ using a 40 mesh basket. Sample no. $108(10 \mathrm{~mL})$ was withdrawn from the dissolution apparatus and replaced with a fresh medium. Sample no. 109 was filtered through a $0.45 \mu \mathrm{m}$ membrane and diluted to a suitable solvent. The absorbance of samples was measured at $346 \mathrm{~nm}$ using a UV spectrophotometer, and cumulative drug release was calculated ${ }^{28}$. Sample no. 110 drug release data were analyzed using PCP Disso software version 2.08. The dissolution profile of all the batches was fitted to zeroorder, first-order, Higuchi, Hixson-Crowell, as well as Korsmeyer and Peppas to ascertain the kinetic modeling of drug release, and the model with the highest correlation coefficient was considered to be the best mode. Results were compared with the USP monograph limits.

Microscopy - Liposomal dispersion was prepared by dispersing spray-dried formulation in phosphate buffer $\mathrm{pH} 6.8$ and was observed under 50X lens under Polarizing microscope. The microscopy revealed the particle size, shape of vesicles (regular or irregular), and free drug crystals ${ }^{29}$. The 50X resolution lens was used for the particle size analysis. In a microscope, 1 unit of the scale present on the lens was taken as $2 \mu$. The required amount of blend was reconstituted with the necessary amount of water, and then the slide was prepared and observed under a microscope.

Related substances (detection of impurity) - This characterization was done to check impurities in the prepared liposomal formulation of isotretinoin $-5,6$ epoxy-13-cis retinoic acid, tretinoin, and others unknown. Some impurities were observed with the related substance test of the liposomal formulation ${ }^{30}$. The results were compared with the USP monograph limits.

\section{RESULTS AND DISCUSSION}

\section{Physical characterization of isotretinoin}

Solubility studies - The isotretinoin was found to be yellowish-orange, crystalline powder with a faint odor that resembles vitamin A. The drug was insoluble in water, whereas it was soluble in the organic solvent, thereby suggesting it was lipophilic. Chloroform : methanol (2: 1 respectively) was taken for the formulation as solvents. Isotretinoin exhibits solubility across the borate buffer $\mathrm{pH} 8$. Therefore, it could be classified as a "less soluble" material. A review of the literature revealed that the drug exhibits high permeability. According to BCS classification, if the highest dose of the drug was insoluble in aqueous media and exhibited high permeability, it was called a BCS class II drug 18 . Therefore, the isotretinoin falls under BCS class II.

Selection of lipids - Excipient for isotretinoin liposomal formulation was selected based on maximum solubility, in which isotretinoin was found to be a lipophilic drug. Batches were prepared and observed under the microscope 50X lens for free drug crystals, and the shape 
and size of vesicles formed to determine the excipient ratios used. Batch no. 1 had shown the presence of free drug crystals while vesicles were irregular in shape. Batch no. 2 had also shown the presence of free drug crystals, and vesicles were also irregular in shape and size. Batch no. 3 had not shown any free drug crystals, but multivesicular structures were regular in round shapes. As observed, batch 3 excipient ratios were selected for the preparation of the liposomal formulation ${ }^{31}$. Clear vesicular structures with no free drug crystals found with HSPC : cholesterol $4: 1$. Therefore, the $4: 1$ ratio was found to be sufficient.

Drug loading - Isotretinoin quantity of $3.1 \mathrm{~mol}$ resulted in powder blend, which contains $40 \mathrm{mg}$ drug in $200 \mathrm{mg}$ blend. Hygroscopicity was observed, and for the collection of spray-dried powder, RH was maintained below $25 \%$. The collected powder was filled in 00 sizes hard gelatin capsule with a suitable amount. Further increase in drug quantity leads to free drug crystals. The drug loading of various batches in different quantities was presented in Table III.

Table III. Microscopic observation for drug loading

\begin{tabular}{|c|c|c|}
\hline Batch & $\begin{array}{c}\text { Isotretinoin } \\
\text { quantity (mol) }\end{array}$ & Observation \\
\hline 1 & 0.25 & $\begin{array}{l}\text { No free drug crystals were found. } \\
\text { Multivesicular structures were } \\
\text { observed but the powder was } \\
\text { sticky because of relative humidity } \\
\text { i.e. } 60 \%\end{array}$ \\
\hline 2 & 0.5 & No free drug crystals, dry powder. \\
\hline 3 & 1 & Relative humidity maintained \\
\hline 4 & 1.4 & below $25 \%$. Large multivesicular \\
\hline 5 & 2.2 & vesicles were found at $50 \mathrm{X}$ \\
\hline 6 & 3.1 & \\
\hline
\end{tabular}

Differential scanning calorimetry - Differential scanning calorimetry study was carried out for isotretinoin and drug-loaded dry liposome's containing lipids (HSPC, DSPG, and cholesterol). The DSC thermograms of isotretinoin and drug-loaded dry liposomes were illustrated in Figures $\mathbf{1}$ and 2, respectively. The DSC thermogram of isotretinoin showed endothermic at $181.73^{\circ} \mathrm{C}$. It proves that the isotretinoin was pure ${ }^{32}$.
The DSC thermogram of drug-loaded dry liposomes with lipids showed endothermic at $76.58^{\circ} \mathrm{C}$. The DSC thermogram of isotretinoin-loaded liposomes composed of HSPC, DSPG, cholesterol, and isotretinoin in the ratio of $4: 1: 0.16: 3.1$, respectively, showed the disappearance of melting endothermic of isotretinoin and major endothermic was observed at $76.58^{\circ} \mathrm{C}$. The absence of the melting endothermic of isotretinoin suggested significant interaction of isotretinoin with lipids leading to enhanced entrapment of the drug ${ }^{33}$. The isotretinoin was dissolved in lipids. The incorporated isotretinoin was associated with lipids and interacted to a large extends with them. The DSC results of liposome's suggested enhanced entrapment efficiency of isotretinoin in a lipid bilayer.

Microscopy - Microscopy of batches was done to observe particle size, shape, and free drug crystals. The particle size multivesicular vesicles of sizes 2 to $60 \mu$ were observed. Figures $\mathbf{3} \mathbf{a}$ and $\mathbf{3} \mathbf{b}$ of SSD 1 microscopy showed that multivesicular vesicles of drug solubilized lipids were found. Free drug crystals were not found. The drug was solubilized entirely in lipids. In Figure 3c of TFHSD 1, microscopy-free drug crystals were found, and the size and shape of the vesicles were also irregular. Thus, the strategy was dropped, but beneficial points were taken into considerations from this strategy, such as this strategy was successfully able to remove hygroscopicity. In Figure 3d of ESD 1, microscopy large lipid vesicles in the aqueous medium were found. No free drug crystals were found.

In SSD 1, no free drug crystals were found, and the vesicles were also in regular shape and size, which states that the drug was utterly solubilized in lipids ${ }^{34}$. In ESD1, large lipid vesicles were found, and no free drug crystals were found. Thus, both these strategies pass the microscopy test. In TFHSD 1, free drug crystals were found, and the vesicles were irregular in shape; this strategy fails the microscopy test. 


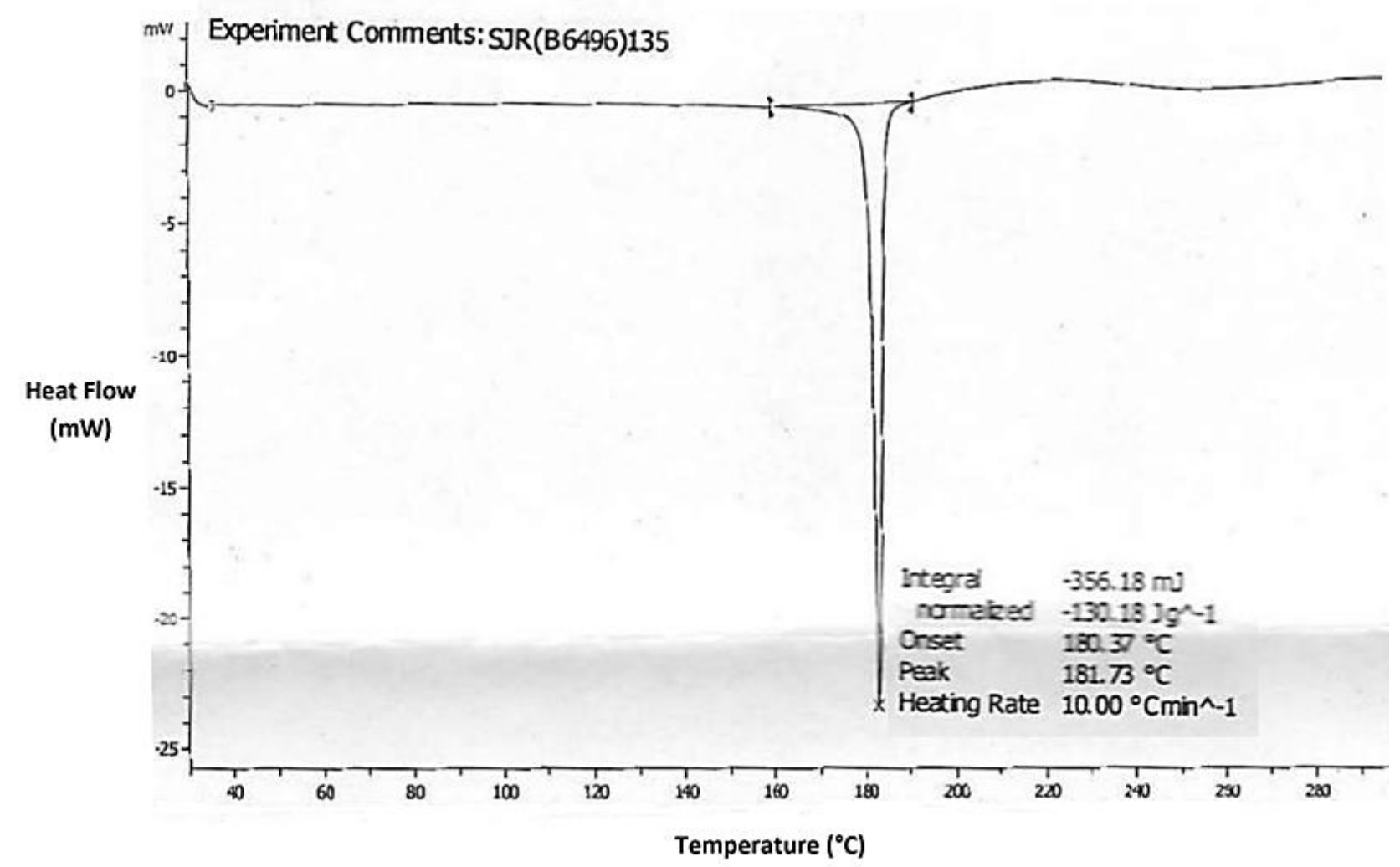

Figure 1. Differential scanning calorimetry thermogram of isotretinoin

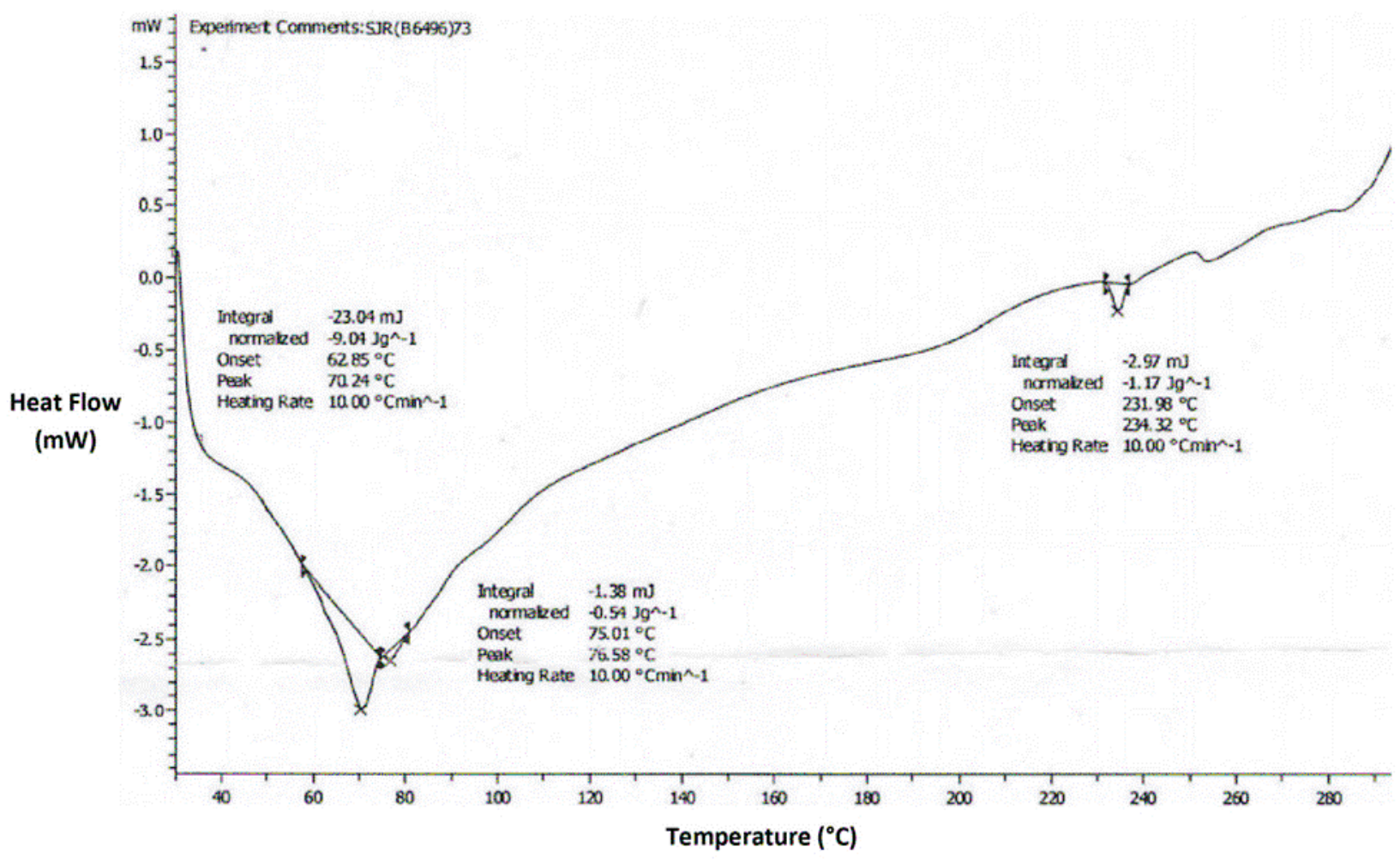

Figure 2. Differential scanning calorimetry thermogram of dry liposomes of isotretinoin and lipids 

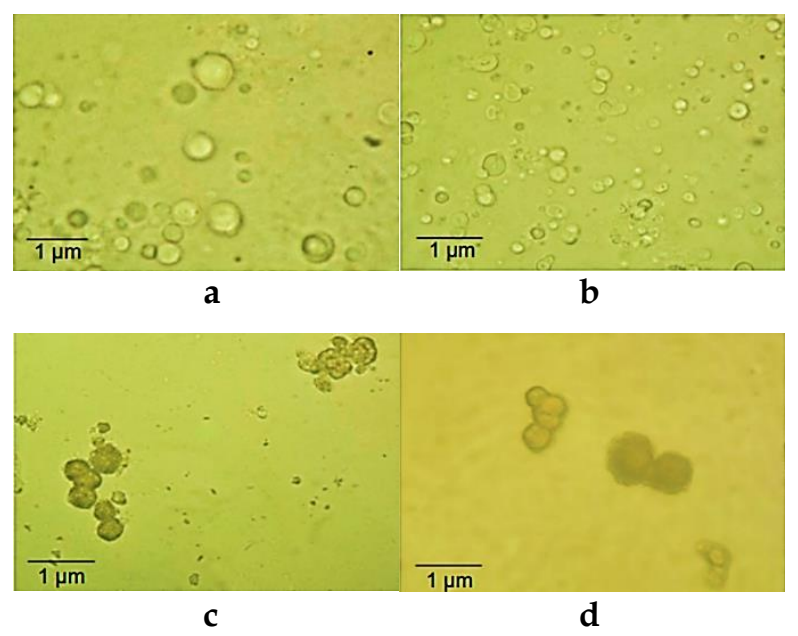

Figure 3. The SEM images of SSD 1 (a and b), TFHSD 1 (c), and ESD 1 (d) taken at 20,000x magnification

Physical characterization of isotretinoin liposomal formulation

Drug content - The formulation should contain not less than $90.0 \%$ and not more than $110.0 \%$ of the labeled amount of drug according to the USP monograph [120]. The triplicate batches were prepared for every strategy, and the assay was also done in triplicate average best assay results ${ }^{35}$. Batch SSD 1 had shown drug content 96.6\%, while batch ESD 1 had shown 91.1\% of drug content. The assayed drug content in formulations ranges from $90.0 \%$ to $110.0 \%$, which were under the USP limit. In vitro drug release - The in vitro drug release studies were performed in borate buffer with pancreatin to determine the release of the drug. The dissolution profiles of all the formulations were determined and shown in Figure 4. The results were analyzed by plotting cumulative drug release/time. The dissolution was done in low intensity of light as the drug was light-sensitive. The dissolution was done in triplicates of each strategy.

The average best results were shown in Figure 4-the dissolution profile of SSD 1 and ESD 1. According to the USP monograph, $70 \%$ of the drug should be released in 90 minutes. Dissolution of SSD 1 batch slow-release, which did not fulfill the USP requirement as there was $61 \%$ release in 90 minutes. Dissolution of ESD 1 batch
95\% release in 90 minutes fulfills USP requirement and shows immediate release action ${ }^{36}$.

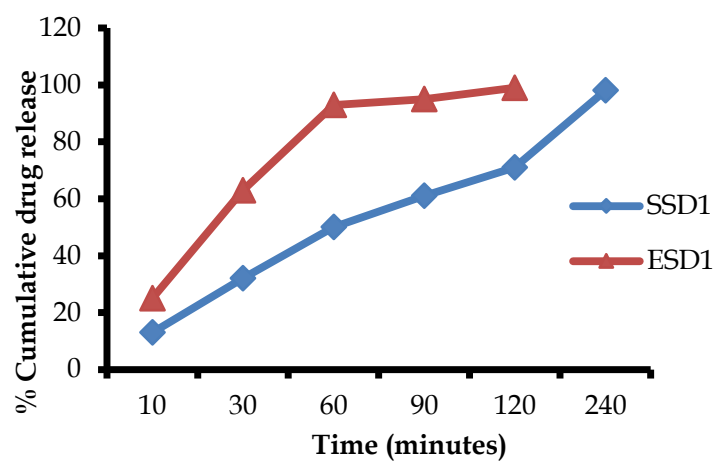

Figure 4. In vitro drug release profile

Related substances - The related substance analysis was done to detect impurity in the formulation, which was compared with the USP limits ${ }^{37}$. The analysis was done in triplicates of each batch, and the best results were given in Table IV. The analysis revealed that the impurities of batch SSD 1 and ESD 1 were according to the USP limits. The impurities of batch THFSD 1 (using nitrogen; $1 \mathrm{~N}$ and using air; 1A) were not found out of the limits of USP.

Table IV. Related substance (impurity testing) data

\begin{tabular}{|c|c|c|c|c|c|}
\hline \multirow[b]{2}{*}{ Impurities } & \multirow{2}{*}{$\begin{array}{c}\text { Limits } \\
(\% \\
\mathrm{w} / \mathrm{w}) \\
\end{array}$} & \multirow[b]{2}{*}{ SSD 1} & \multicolumn{2}{|c|}{ TFHSD 1} & \multirow[b]{2}{*}{ ESD 1} \\
\hline & & & $\begin{array}{c}1 \mathrm{~N} \\
\text { (nitrogen) }\end{array}$ & 1A (air) & \\
\hline $\begin{array}{l}\text { 5,6-epoxy-13-cis } \\
\text { retinoic acid } \\
\text { (peak } 1 \text { and } 2 \text { ) }\end{array}$ & 0.5 & $0.22 \pm 0.1$ & $0.11 \pm 0.3$ & $1.2 \pm 0.5$ & $0.05 \pm 0.1$ \\
\hline Tretinoin & 0.2 & $0.07 \pm 0.2$ & $0.38 \pm 0.5$ & $0.36 \pm 0.3$ & $0.14 \pm 0.1$ \\
\hline Highest unknown & 0.1 & $0.07 \pm 0.1$ & $0.07 \pm 0.2$ & $0.1 \pm 0.1$ & $0.05 \pm 0.1$ \\
\hline Total unknown & 0.5 & $0.24 \pm 0.4$ & - & - & $0.14 \pm 0.3$ \\
\hline $\begin{array}{l}\text { Total related } \\
\text { substances }\end{array}$ & 1.5 & $0.53 \pm 0.2$ & - & - & $0.33 \pm 0.4$ \\
\hline
\end{tabular}

\section{CONCLUSION}

Dry liposomes of isotretinoin were successfully prepared using three different strategies of spray drying, i.e., SSD, TFHSD, and ESD. The formulation of each respective strategy was analyzed. Related substance (impurity study) revealed that the impurities of SSD and ESD were under the USP limits, whereas the impurities of TFHSD were out of USP limits, so the formulation of two strategies SSD and ESD, were further analyzed. Therefore, a liposomal formulation of isotretinoin 
through ESD was found successful, time-effective, and cost-effective in comparison with the other two strategies.

\section{ACKNOWLEDGMENT}

The authors are thankful to Professor Teerapol Srychana, Prince of Songkla University, Hatyai, Thailand, for motivation, guiding, and checking the English language of the paper.

\section{AUTHORS' CONTRIBUTION}

Md. Iftekhar Ahmad: Conceptualization, Project administration, Supervision, Investigation; Punet Kumar: Formal Analysis, Funding acquisition, Data curation, Methodology, Resources, Software; Sangam Singh: Validation, Visualization, Writing - original draft; Nitin Kumar: Writing - review \& editing.

\section{DATA AVAILABILITY}

All data are available from the authors.

\section{CONFLICT OF INTEREST}

The authors declare no conflict of interest or otherwise.

\section{REFERENCES}

1. Ahmad MI, Keach JW, Behl T, Panichayupakaranant P. Synergistic effect of a-mangostin on antibacterial activity of tetracycline, erythromycin, and clindamycin against acne involved bacteria. Chin Herb Med. 2019;11(4):412-6. doi:10.1016/j.chmed.2019.03.013

2. Mehta PP, Ghoshal D, Pawar AP, KadamSS, DhaptePawar VS. Recent advances in inhalable liposomes for treatment of pulmonary diseases: Concept to clinical stance. J Drug Deliv Sci Technol. 2020;56(A):101509. doi:10.1016/j.jddst.2020.101509

3. Tan AU, Schlosser BJ, Paller AS. A review of diagnosis and treatment of acne in adult female patients. Int J Womens Dermatol. 2018;4(2):56-71. doi:10.1016/j.ijwd.2017.10.006
4. Rathi SK. Acne Vulgaris Treatment : The Current Scenario. Indian J Dermatol. 2011;56(1):7-13. doi:10.4103/0019-5154.77543

5. Khalil NY, Darwish IA, Al-Qahtani AA. Chapter Five - Isotretinoin. Profiles Drug Subst Excip Relat Methodol. 2020;45:119-57.

doi:10.1016/bs.podrm.2019.10.005

6. Tran PT, Berman HS, Leavitt E, Hogeling M, Cheng CE. Analysis of factors associated with relapse in patients on their second course of isotretinoin for acne vulgaris. J Am Acad Dermatol. 2021;84(3):856-9. doi:10.1016/j.jaad.2020.10.030

7. De Holanda PMM, Guilherme K, Barbosa N, Menezes PDL, Nóbrega DF, Dos Santos AF, et al. Salivary Changes Arising from Anti Acne Therapy with Isotretinoin Oral Use: A Systematic Review with Meta-Analyses. Oral Surg Oral Med Oral Pathol Oral Radiol. 2020;130(3):e253. doi:10.1016/j.oooo.2020.04.666

8. Marson JW, Baldwin HE. An Overview of Acne Therapy, Part 2: Hormonal Therapy and Isotretinoin. Dermatol Clin. 2019;37(2):195-203. doi:10.1016/j.det.2018.12.002

9. Sadeghzadeh-Bazargan A, Ghassemi M, Goodarzi A, Roohaninasab M, Nobari NN, Behrangi E. Systematic review of low-dose isotretinoin for treatment ofacne vulgaris: Focus on indication, dosage, regimen, efficacy,safety, satisfaction, and follow up, based on clinical studies. Dermatol Ther. 2021;34:e14438. doi:10.1111/dth.14438

10. Costa CS, Bagatin E, Martimbianco ALC, da Silva EM, Lúcio MM, Magin P, et al. Oral isotretinoin for acne. Cochrane Database Syst Rev. 2018;11(11):CD009435. doi:10.1002/14651858.cd009435.pub2

11. Kuznetsova DA, Gabdrakhmanov DR, Gaynanova GA, Vasileva LA, Kuznetsov DM, Lukashenko SS, et al. Novel biocompatible liposomal formulations for encapsulation of hydrophilic drugs Chloramphenicol and cisplatin. Colloids Surf A Physicochem Eng Asp. 2021;610:125673. doi:10.1016/j.colsurfa.2020.125673

12. Ansar SM, Mudalige T. Characterization of doxorubicin liposomal formulations for size-based distribution of drug and excipients using asymmetric-flow field-flow fractionation (AF4) and liquid chromatography-mass spectrometry (LC-MS). 
Int J Pharm. 2020;574:118906. doi:10.1016/j.ijpharm.2019.118906

13. Sonkar R, Sonali, Jha A, Viswanadh MK, Burande AS, Narendra, et al. Gold liposomes for brain-targeted drug delivery: Formulation and brain distribution kinetics. Mater Sci Eng C. 2021;120:111652. doi:10.1016/j.msec.2020.111652

14. Liu W, Hou Y, Jin Y, Wang Y, Xu X, Han J. Research progress on liposomes: Application in food, digestion behavior and absorption mechanism. Trends Food Sci Technol. 2020;104:177-89. doi:10.1016/j.tifs.2020.08.012

15. Leitgeb M, Knez Ž, Primožič M. Sustainable technologies for liposome preparation. J Supercrit Fluids. 2020;165:104984. doi:10.1016/j.supflu.2020.104984

16. Shah S, Dhawan V, Holm R, Nagarsenker MS, Perrie Y. Liposomes: Advancements and innovation in the manufacturing process. Adv Drug Deliv Rev. 2020;154-155:102-22. doi:10.1016/j.addr.2020.07.002

17. Filipczak N, Pan J, Yalamarty SSK, Torchilin VP. Recent advancements in liposome technology. Adv Drug Deliv Rev. 2020;156:4-22. doi:10.1016/j.addr.2020.06.022

18. Papich MG, Martinez MN. Applying Biopharmaceutical Classification System (BCS) Criteria to Predict Oral Absorption of Drugs in Dogs: Challenges and Pitfalls. AAPS J. 2015;17(4):948-64. doi:10.1208/s12248-015-9743-7

19. Jadhav K, Dhamecha D, Tate A, Tambe H, Patil MB. Application of UV spectrophotometric method for easy and rapid estimation of lafutidine in bulk and pharmaceutical formulation. Pharm Methods. 2011;2(4):264-7. doi:10.4103/2229-4708.93398

20. Singh R, Lillard Jr JW. Nanoparticle-based targeted drug delivery. 2009. Exp Mol Pathol. 86(3):215-23. doi:10.1016/j.yexmp.2008.12.004

21. Durowoju IB, Bhandal KS, Hu J, Carpick B, Kirkitadze M. Differential Scanning Calorimetry - A Method for Assessing the Thermal Stability and Conformation of Protein Antigen. J Vis Exp. 2017;121:55262. doi:10.3791/55262

22. Ji W, Li X, Wang J, Ye B, Wang C. Preparation and Characterization of the Solid Spherical HMX/F2602 by the Suspension Spray-Drying Method. J Energ
Mater. doi:10.1080/07370652.2015.1095813

2016;34(4):357-67.

23. Varina S, Martin A, Cocero MJ. Liposomal Incorporation of Lavandin Essential Oil by a ThinFilm Hydration Method and by Particles from GasSaturated Solutions. Ind Eng Chem Res. 2011;50(4):2088-97. doi:10.1021/ie102016r

24. Zhang H. Thin-Film Hydration Followed by Extrusion Method for Liposome Preparation. Methods Mol Biol. 2017;1522:17-22. doi:10.1007/9781-4939-6591-5_2

25. Maniyar MG, Kokare CR. Formulation and evaluation of spray dried liposomes of lopinavir for topical application. J Pharm Investig. 2019;49:259-70. doi:10.1007/s40005-018-0403-7

26. Juttulapa M, Piriyaprasarth $S$, Takeuchi H, Sriamornsak P. Effect of high-pressure homogenization on stability of emulsions containing zein and pectin. Asian J Pharm Sci. 2017;12(1):21-7. doi:10.1016/j.ajps.2016.09.004

27. Eroğlu İ, Aslan M, Yaman Ü, Gultekinoglu M, Çalamak S, Kart D, et al. Liposome-based combination therapy for acne treatment. J Liposome Res. 2020;30(3):263-73. doi:10.1080/08982104.2019.1630646

28. MadanS, Nehate C, Barman TK, Rathore AS, Koul V. Design, preparation, and evaluation of liposomal gel formulations for treatment of acne: in vitro and in vivo studies. Drug Dev Ind Pharm. 2019;45(3):395404. doi:10.1080/03639045.2018.1546310

29. Benne N, Leboux RJT, Glandrup M, van Dujin J, Vigario FL, Neustrup MA, et al. Atomic force microscopy measurements of anionic liposomes reveal the effect of liposomal rigidity on antigenspecific regulatory $\mathrm{T}$ cell responses. J Control Release. 2020;318:246-55. doi:10.1016/j.jconrel.2019.12.003

30. Weber F, Rahnfeld L, Luciani P. Analytical profiling and stability evaluation of liposomal drug delivery systems: A rapid UHIPLC-CAD-based approach for phospholipids in research and quality control. Talanta. 2020;220:121320. doi:10.1016/j.talanta.2020.121320

31. FranzéS, Selmin F, Samaritani E, Minghetti P, Cilurzo F. Lyophilization of Liposomal Formulations: Still Necessary, Still Challenging, Pharmaceutics. 2018;10(3):139. doi:10.3390/pharmaceutics10030139 
32. Layegh P, Mosallaei N, Bagheri D, Jaafari MR, Golmohammadzadeh $\mathrm{S}$. The efficacy of Isotretinoinloaded solid lipid nanoparticles in comparison to Isotrex ${ }^{\circledR}$ on acne treatment. Nanomed J. 2013;1(1):3847.

33. Sarkar T, Sarkar S, Patra A. Low-dose isotretinoin therapy and blood lipid abnormality: A case series with sixty patients. J Family Med Prim Care. 2018;7(1):171-4. doi:10.4103/jfmpc.jfmpc_104_16

34. Akbarzadeh A, Rezaei-Sadabady R, Davaran S, Joo SW, Zarghami N, Hanifehpour Y, et al. Liposome: classification, preparation, and applications. Nanoscale Res Lett. 2013;8(1):102. doi:10.1186/1556276X-8-102

35. Vranić E, Uzunović A. Study of The Applicabilty of Content Uniformity and Dissolution Variation Test on Ropinirole Hydrochloride Tablets. Bosn J Basic Med Sci. 2008;8(2):193-200. doi:10.17305/bjbms.2008.2981

36. Nurhikmah W, Sumirtapura YC, Pamudji JS. Dissolution Profile of Mefenamic Acid Solid Dosage Forms in Two Compendial and Biorelevant (FaSSIF) Media. Sci Pharm. 2016;84(1):181-90. doi:10.3797/scipharm.ISP.2015.09

37. Taylor PW, Keenan MHJ. Pharmaceutical quality of generic isotretinoin products, compared with Roaccutane. Curr Med Res Opin. 2006;22(3):603-15. doi:10.1185/030079906x96326 